
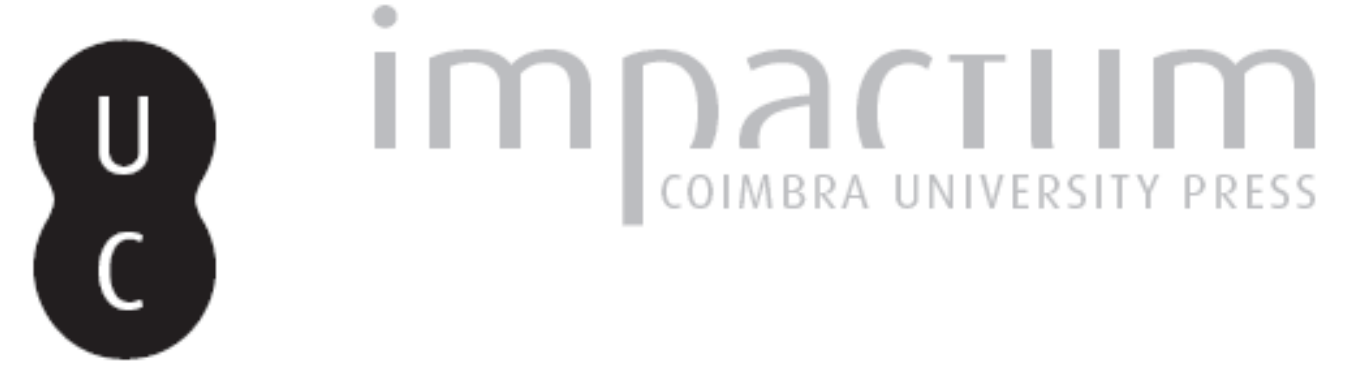

\title{
Portugal e o turismo: o seu posicionamento estratégico em relação aos mercados potenciais e as perspetivas de desenvolvimento futuro
}

Autor(es): Jordan, André

Publicado por: Imprensa da Universidade de Coimbra

URL persistente:

URI:http://hdl.handle.net/10316.2/38319

DOI:

DOI:http://dx.doi.org/10.14195/0871-1623_34_9

Accessed : $\quad$ 26-Apr-2023 14:00:50

A navegação consulta e descarregamento dos títulos inseridos nas Bibliotecas Digitais UC Digitalis, UC Pombalina e UC Impactum, pressupõem a aceitação plena e sem reservas dos Termos e Condições de Uso destas Bibliotecas Digitais, disponíveis em https://digitalis.uc.pt/pt-pt/termos.

Conforme exposto nos referidos Termos e Condições de Uso, o descarregamento de títulos de acesso restrito requer uma licença válida de autorização devendo o utilizador aceder ao(s) documento(s) a partir de um endereço de IP da instituição detentora da supramencionada licença.

Ao utilizador é apenas permitido o descarregamento para uso pessoal, pelo que o emprego do(s) título(s) descarregado(s) para outro fim, designadamente comercial, carece de autorização do respetivo autor ou editor da obra.

Na medida em que todas as obras da UC Digitalis se encontram protegidas pelo Código do Direito de Autor e Direitos Conexos e demais legislação aplicável, toda a cópia, parcial ou total, deste documento, nos casos em que é legalmente admitida, deverá conter ou fazer-se acompanhar por este aviso.

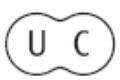




\title{
Portugal e o Turismo. 0 seu posicionamento estratégico em relação aos mercados potenciais e as perspetivas de desenvolvimento futuro ${ }^{1}$ Portugal and tourism. Strategic positioning in potential markets and prospects for future development
}

\author{
André Jordan
}

Presidente do André Jordan Group

1.

Estou muito honrado em poder participar nesta cerimónia de abertura do ano letivo dos alunos de licenciatura, mestrado e doutoramento em Turismo, Lazer e Património.

Agradeço ao Departamento de Geografia da Faculdade de Letras da Universidade de Coimbra e ao Professor Paulo Nuno Nossa esta oportunidade de dialogar com a nova geração sobre os desafios que enfrentamos.

\section{2.}

Poderia contar-vos histórias da minha experiência ao longo de 65 anos de trabalho em várias partes do mundo.

Porém, considero que, no momento que atravessamos num mundo conturbado, será mais produtivo refletir convosco sobre o posicionamento estratégico de Portugal em relação aos mercados potenciais do Turismo e as perspetivas de desenvolvimento futuro.

Interpreto este convite como uma honra que fico a dever aos muitos anos em que trabalho no Imobiliário Turístico e à experiência que fui acumulando.

Aprendi a valorizar, igualmente, a estabilidade dos projetos e a sua flexibilidade, ou seja a capacidade de adaptação a diferentes tempos, desafios, culturas e conjunturas.

Os mercados são hoje muito diferentes do que eram nos anos 70 do século passado, quando iniciei o projeto da Quinta do Lago.

Mas já naquela época eu precisei de ir em busca de um mercado de muito alto nível, de enorme potencialidade, quando todos se orientavam para a proverbial competição com os nossos vizinhos espanhóis pelos segmentos inferiores.

Quase quatro décadas percorridas, a Quinta do Lago continua a ser uma jóia rara no panorama do turismo internacional, recorrentemente referida pelos especialistas como o melhor empreendimento da sua natureza em todo o mundo.

Chamo este exemplo à nossa reflexão para destacar a ideia de que os produtos turísticos que projetamos hoje só terão sucesso se tiverem o potencial de atração sustentável dos clientes que estrategicamente selecionarmos como alvo.
Para isso precisamos de um bom diagnóstico da realidade onde vamos intervir, de pensamento e planeamento estratégico e de visão de futuro.

Para evitar flutuações críticas nos fluxos turísticos e os desequilíbrios económicos e sociais que eles provocam, precisamos de um bom conhecimento dos clientes potenciais que queremos conquistar, de forma sustentável.

Sabemos que vivem e trabalham em cidades, climas e condições geográficas e familiares diferentes das nossas.

Mas saberemos o que procuram quando nos visitam? Que impulso os levou a visitar-nos?

Que expectativas criaram?

Fomos capazes de satisfazer essas expectativas? Será que eles vão voltar?

E recomendarão Portugal aos seus amigos?

3.

Devemos ser muito ponderados no equilíbrio que procuramos entre qualidade e quantidade.

Há muito que venho tentando alertar para os riscos da sobrevalorização da explosão de turistas nas nossas grandes cidades.

Mas fico sempre com a amarga sensação de ser apenas um pregador no deserto...

Os números parecem bons, revelam crescimento do mercado, mas este boom quantitativo não esconderá uma ameaça para o futuro?

4.

Vamos então por partes...

Começando pela oportunidade.

Portugal tem realmente uma oportunidade de se afirmar no mercado do turismo mundial e no mercado residencial internacional, seja de habitação permanente, seja temporária.

Não devemos confundir o aumento de receitas com resultados económicos, e o mesmo em relação ao aumento do emprego.

Temos de reforçar as campanhas de atração dos segmentos mais rentáveis dos mercados, porquanto é nesses que somos realmente competitivos.

Temos a vantagem de que não precisamos de grandes volumes de visitantes, dada a dimensão de Portugal.

\footnotetext{
Conferência proferida no Seminário de Abertura do Ano Letivo de 2015/2016, organizado no dia 2 de outubro pelo Departamento de Geografia e Turismo da Faculdade de Letras da Universidade de Coimbra.
} 
Precisamos sim de atraí-los e fidelizá-los nos vários segmentos, que vão desde o short-break ao turismo residencial, que fixa o visitante como um cliente permanente.

Para isso podem concorrer medidas eventuais de política, como é o caso dos "vistos gold" ou regimes excecionais de benesses fiscais.

Mas há fatores estruturais, que me proponho enumerar por ordem de importância.

Primeiro: o clima.

Os países árabes não inventaram o petróleo. Encontraram-no no subsolo...

Nós também não inventámos o melhor e o mais saudável clima do mundo!

Mas temos o direito de explorá-lo e a obrigação de conservá-lo, defendendo a qualidade do ambiente.

Segundo: a segurança.

Estar na periferia nem sempre é uma desvantagem.

Num cenário mundial de grande intranquilidade, com guerras sem fim à vista, terrorismo sem fronteiras, atentados dos fundamentalistas religiosos com muitas vítimas e agora a vaga imensa de refugiados, Portugal ainda é um porto seguro.

As pessoas podem passear tranquilas nas ruas das nossas cidades e as infraestruturas são de uma forma geral modernas e seguras.

Em terceiro lugar, a culinária.

Apesar de não haver entre nós uma tradição de gastronomia sofisticada, temos alguns nomes reconhecidos internacionalmente.

Temos boa matéria-prima, sobretudo o peixe e os mariscos frescos.

Temos bons vinhos.

"The Wine Spectator", a bíblia deste sector, escolheu este ano um Porto, o Dow's 2011, como o melhor vinho do mundo.

E no terceiro e quarto lugar estão dois vinhos de mesa do Douro.

A importância deste facto é posicionar Portugal numa faixa de alta qualidade.

A nossa culinária beneficia ainda de azeites de primeiríssima qualidade e de uma grande variedade de ervas aromáticas, muito presentes nas receitas tradicionais.

Temos uma doçaria de grande originalidade e pratos típicos que cativam e conquistam o paladar dos visitantes.

\section{Em quarto lugar...}

... entre os fatores competitivos para o nosso turismo, colocaria ainda o povo, que é de uma forma geral correto e prestativo.

Tratamos bem os estrangeiros e temos uma nova geração que domina bem o inglês.

Finalmente, temos bons preços.

0 que vem a ser muito importante para a competitividade das faixas mais altas do mercado.
Não tanto para os segmentos mais baixos, porque eles são muito menos elásticos.

A atestar este facto está o que aconteceu com o aumento de preços que o sucesso trouxe:

Verificamos que a estadia média dos turistas de short-break baixou de três para dois dias.

Não há dinheiro para mais...

5.

Mas há um fator muito negativo e que sempre nos deixa para trás na comparação com a Espanha:

Ao contrário do que é a convicção generalizada, Portugal não é propriamente um destino conhecido.

Há um clima simpático, no Mundo, em relação a Portugal.

Mas Portugal continua a ser, nos grandes mercados que nos interessam, uma coisa difusa...

Isto resulta de não haver uma estratégia a que corresponda um plano de ação e promoção de vendas.

Tal como não há um marketing efetivo e concertado de Portugal como destino turístico, e não há uma programação bem calendarizada de eventos que atraiam as pessoas para Portugal com regularidade.

Vou dar um exemplo concreto.

Estive há pouco tempo com um grupo de milionários franceses que encontraram Portugal e já cá estão, com residências permanentes ou temporárias.

Os comentários que ouvi foram muito positivos. Mas uma observação foi recorrente:

"Temos tanta pena que os nossos amigos não saibam como isto é bom!"

Os amigos milionários destes franceses estão a ir para a Bélgica, para Miami, para Espanha... porque Portugal não está ainda no mapa dos destinos possíveis para um turismo residencial de alto nível.

6.

Não se está a fazer o trabalho de promoção internacional que eu precisei de fazer em relação à Quinta do Lago e à recuperação de Vilamoura e que foram a chave do seu sucesso.

Um esforço que só não fizemos ainda para o Belas Clube de Campo, em Sintra, aonde já vivem 650 famílias, porque a crise internacional e demoras burocráticas na aprovação do plano de urbanização da zona vieram travar a caminhada.

Estamos agora preparando o relancamento nacional e internacional do Belas Clube de Campo para a próxima Primavera.

Belas é um lugar desconhecido no Mundo, uma jóia da Natureza situada entre as maravilhas paisagísticas e patrimoniais de Sintra e o bulício de Lisboa, a 20 minutos do centro de Lisboa, de Cascais e do aeroporto.

Pôr o Belas Clube de Campo no mapa internacional do imobiliário turístico representa um grande desafio, comparável ao que foi, nos Anos 70, pôr a Quinta do Lago nas bocas do Mundo e no horizonte do jet-set.

Sugiro que estejam atentos ao que irá aparecendo sobre o empreendimento, que conta com uma infraestrutura que inclui um magnífico campo de 
golfe, ténis, futebol, ginásio com piscina coberta, etc.

\section{7.}

Voltemos à nossa reflexão sobre a situação do Turismo em Portugal.

Aqueles que resistem à ideia da imperatividade deste grande esforço de promoção internacional fazem-no por pura ignorância.

Não sabem, não percebem o mundo em que vivemos e teimam em agarrar-se a sucessos conjunturais, com a aposta em políticas que comprometem a sustentabilidade económica do sector e dos seus agentes.

Se prosseguirem neste caminho, outros mercados concorrentes agarrarão a oportunidade, e mais uma vez ficaremos com resultados medíocres, quando poderíamos fazer do sector do Turismo e do Imobiliário Turístico a grande alavanca para a recuperação da economia, do emprego e do Estado Social, que foi o tema obrigatório de debate na campanha eleitoral que hoje encerra.

As autoridades do sector têm mostrado pouco interesse na realização de eventos mobilizadores, apostados que estão no marketing virtual.

Tive o prazer, esta semana, de verificar que dois eventos ligados à realidade virtual vão ter os seus congressos em Lisboa. O primeiro é o Web Summit que vai reunir $40 \mathrm{mil}$ nerds em Lisboa durante vários dias, no que é já o maior evento neste novo sector.

Afinal, os utilizadores da Web sentem a necessidade do contacto humano.

O outro evento é o inRetail Congress - Digital Revolution, que reunirá em Novembro os craques do retalho e da distribuição.

Os eventos são um segmento de mercado de grande importância.

É o que está acontecendo neste justo momento em Espanha.

Com o aumento do número de turistas e a emergência de uma nova vaga de pessoas que vivem do turismo, nomeadamente através do alojamento local, criou-se uma certa moda e a ideia de que tudo se resolve com internet e preços baixos. ropa!

Portugal é hoje o destino mais barato na Eu-

Uma honrosa exceção são Cascais e o Estoril, cujas autoridades e empresários optaram pela realização e apoio a eventos de qualidade e repercussão, com o resultado de que essas duas localidades têm os preços mais altos e a mais alta ocupação anual do país.

Os eventos em questão são diversificados na sua natureza incluindo sectores como a economia, a política internacional, as artes, eventos sociais e desportos como a vela e o hipismo.

As pessoas que invadiram a baixa de Lisboa vieram pelo preço e por pouco tempo.

Com esta política, cada categoria hoteleira tende a concorrer com a categoria inferior, até chegarmos ao preço do alojamento local, que se caracteriza pelo défice de profissionalismo, pela ausência de serviço e pela falta da faturação associada ao serviço.
Como não se estimula a procura ao nível das categorias mais elevadas, as taxas de ocupação continuam insatisfatórias.

E quando denunciamos esta evidência, respondem-nos com os números de Agosto, numa conjuntura este ano muito favorecida pelos problemas na Grécia, na Turquia e no Médio Oriente!

O problema está nos outros onze meses...

8.

O proselitismo que eu tenho tentado fazer em prol de uma nova atitude de cariz estratégico e orientada para a sustentabilidade do Turismo não tem tido o impacte que é desejável, porque as pessoas preferem acreditar que vivemos no paraíso.

Infelizmente é um paraíso low-cost...

Além de não dar lucro, é uma coisa que estes turistas só fazem uma vez.

Não viveram nenhuma experiência marcante que os faça voltar, a menos que os preços continuem a baixar e as crises humanitárias se perpetuem no Mediterrâneo!

9.

Temos ainda os hoteleiros, que por vezes não percebem o seu próprio fenómeno e que não dão a devida atenção às armadilhas decorrentes da segmentação do mercado, com a tentação permanente de ir à conquista do número e não do valor.

O Turismo vive de segmentos e cada um deve concorrer com o seu correspondente noutros destinos, e não internamente.

Internamente, cada segmento não deve atrapalhar o outro, mas sim usá-lo em sinergia e complementarmente.

No fim da tabela está o segmento low-cost, city break ou short break.

Gente com pouco tempo, pouca disponibilidade para surpresas e baixa expectativa.

Procuram o que é muito barato.

Quando são jovens, ficam nos hostels, onde camaratas para grupos improváveis se tornam muitas vezes espaços de convívio íntimo pouco recomendáveis...

Temos a seguir o alojamento local, "chez l'habitant" como dizem os franceses.

Pessoas que têm espaço nas suas casas, ou proprietários de apartamentos, alojam turistas em regime de self-service e selfcatering.

Não existe qualquer espécie de serviço, nem arrumação nem limpezas.

O apartamento só é limpo quando a pessoa sai, para o cliente seguinte.

No alojamento local, normalmente falamos de famílias com crianças que não vão para o hotel, porque é mais barato alugar um T1 ou um T2 do que dois ou três quartos de hotel, mesmo de baixa categoria.

O cliente de hotel, mesmo quando procura um 2 ou 3 estrelas, procura serviço.

Pode ser um casal, uma família ou empresas que precisam de alojar um colaborador que vem para uma reunião ou para uma missão mais prolongada. 
Aqui as categorias vão-se segmentando pelo poder de compra das famílias e pelo nível dos colaboradores que as empresas precisam de alojar.

Não vou alongar-me sobre este tema, mas devo dizer-vos que hotéis e alojamento local não são concorrentes entre si.

\section{0.}

E assim chegamos ao topo da tabela: o turismo residencial.

O cliente do turismo residencial é aquele que gostou do destino, gostou do clima, gostou do ambiente e quer fixar-se mesmo que temporariamente num determinado local.

A sua escolha pode ser um apartamento no centro ou na periferia de Lisboa ou do Porto, mas também pode ser um monte no Alentejo, uma moradia na paisagem de um campo de golfe ou uma mansão à beira mar no Algarve.

Em qualquer dos casos, o turista passa a ser um investidor.

E é o turista ideal porque de cliente de passagem, temporário e incerto, passa a ser um turista permanente!

Esteve ontem, está hoje e estará amanhã, porque os fatores endógenos de atratividade do país não se alteram com facilidade.

Não requerendo investimento contínuo para atraí-lo, é um contribuinte líquido de divisas que entram no país para pagar impostos e sustentar a sua vida e a manutenção da propriedade.

O imobiliário turístico foi combatido fora e dentro dos governos durante anos e anos porque "era um horror, porque não era turismo!"

Foi combatido também pelos hoteleiros, o imobiliário e o hoteleiro são complementares, existem cada vez mais projetos que combinam as duas vertentes.

11.

Pensemos agora em termos da economia nacional, no seu todo. Que queremos nós?

Superar a crise e prosperar ou apenas sobreviver?

Penso que este é o momento de acordar para a realidade e iniciar um processo sério de captação de mercados, com sustentabilidade e potencial de crescimento.

A minha proposta concreta tem sido a de uma grande campanha promocional de Portugal nos mercados internacionais, dirigida a segmentos específicos.

Para a desenhar, devemos fazer apelo aos melhores especialistas internacionais em estratégia de marketing e publicidade.

Terá de ser uma campanha plural nas formas e conteúdos, adaptada às diferentes realidades e culturas onde precisamos de captar visitantes.

Aos que argumentam que não há recursos, que o Governo não vai tomar uma iniciativa dessa dimensão e que os empresários também não têm capacidade financeira para uma tal aventura, eu digo que esses recursos existem.
Proponho um acordo de parceria entre o Governo e os empresários do sector com a criação de um fundo específico para esse fim, gerido pelos empresários, sob controlo permanente de uma autoridade pública.

Este fundo será alimentado com a afetação de $1 \%$ das receitas do IVA no sector do Turismo.

Com esta articulação de recursos e interesses, podemos garantir que a gestão das campanhas e eventos promocionais de Portugal serve efetivamente a captação de clientes para os operadores turís ticos aos diversos níveis.

Teremos campanhas e eventos mais orientados para o cliente, mais assertivas e cuja componente institucional deve ser equilibrada.

Mas teremos também, através do controlo público, a garantia de que o dinheiro é bem aplicado, sem desperdícios nem desvios.

Este acordo de parceria entre o Estado e os empresários do sector deverá ter objetivos bem identificados, qualitativa e quantitativamente, de forma a ser fácil a sua avaliação contínua e a tomada das medidas de afinação que se mostrem necessárias.

Finalmente, também deverá obedecer a um calendário realista e rigoroso.

No final do processo, todos ficarão a ganhar:

Os empresários têm condições acrescidas para o sucesso dos seus projetos, numa perspetiva de qualidade e sustentabilidade.

E o Estado vai recuperar os valores que afetar a estas campanhas, através do aumento das receitas pelo crescimento e valorização do Turismo, para além de todas as vantagens inerentes à criação de emprego e diversificação das atividades económicas.

Acredito que a avaliação final do processo permitirá o lançamento de futuras campanhas em condições ainda mais favoráveis.

Uma excelente notícia é que no Porto, a Associação de Turismo do Porto e Norte e a Associação de Empresários para o Desenvolvimento do Turismo Cultural no Porto, unem os seus esforços e investimentos, estando anunciado que também será integrado o Departamento de Turismo da Câmara.

Os empresários não devem ter medo de trabaIhar com os organismos do Governo, o mesmo sendo verdadeiro em relação ao Governo com os privados.

Nesse sentido, vale a pena ler o livro da Mariana Mazzucato, O Estado Empreendedor. Desmas carando o Mito do Setor Público vs o Setor Privado.

12.

Quando se fazem grandes projetos, é comum enfrentarmos uma incompreensão inicial.

Entre todos os obstáculos a vencer, o preconceito contra o desconhecido é um dos mais frustrantes e contra ele só a prova dos factos é eficaz.

Deixo-vos com esta proposta e com os votos dos maiores sucessos nos vossos estudos.

Fico agora à vossa disposição para responder a qualquer pergunta que me queiram fazer. Muito obrigado.

2.10.2015 